\title{
ОРГАНИЗАЦИЯ ТЕХНИЧЕСКОГО ОБСЛУЖИВАНИЯ И РЕМОНТА БАЗОВОГО ШАССИ ПОЖАРНО-СПАСАТЕЛЬНЫХ АВТОМОБИЛЕЙ
}

\author{
Широухов Александр Валерьевич \\ кандидат технических наук, \\ доцент кафедры механики и инженерной графики \\ Санкт-Петербургского университета \\ Государственной противопожарной службы \\ Министерства РФ \\ Фитисов Сергей Анатольевич \\ Магистрант, \\ заместитель начальника пожарно-спасательной \\ части №3 пожарно-спасательного отряда \\ Федеральной противопожарной службы \\ Государственной противопожарной службы
}

Аннотация: В статье рассмотрено современное состояние вопроса организации технического обслуживания и ремонта (далее ТО и Р) пожарноспасательных автомобилей. Рассмотрены причины необходимости определения и корректировки нормативов проведения ТО и Р.

Ключевые слова: Техническое обслуживание и ремонт; трудоемкость; периодичность.

\section{ORGANIZATION OF MAINTENANCE AND REPAIR OF THE BASE CHASSIS OF FIRE AND RESCUE VEHICLES}

\section{Shiroukhov Alexander V. Fitisov Sergey A.}

\footnotetext{
Abstract: The article discusses the current state of the issue of organizing maintenance and repair (hereinafter M\&R) of fire and rescue vehicles. The reasons for the need to determine and adjust the standards for maintenance and repair are considered.
}

Key words: Maintenance and repair; labor intensity; periodicity. 


\section{СОВРЕМЕННЫЕ ТЕХНОЛОГИИ: ПРОБЛЕМЫ ИННОВАЦИОННОГО РАЗВИТИЯ И ВНЕДРЕНИЯ РЕЗУЛЬТАТОВ}

К пожарно-спасательным автомобилям должны предъявляться строгие требования к техническому состоянию их систем и агрегатов. При этом предъявляя особое внимание организации надежной работы узлов, необходимо учитывать экономическую сторону эксплуатации, такую как уменьшение затрат на техническое обслуживание и ремонт систем и агрегатов автомобилей, снижение трудоемкости работ ТО и Р.

Обеспечив высокую техническую готовность и безопасность движения пожарно-спасательных автомобилей путем своевременного обнаружения, и устранения неисправностей при ТО и Р возможно снизит снижению убытков от пожаров. Поэтому совершенствование организации технического обслуживания и ремонта пожарно-спасательных автомобилей является важной задачей в работе МЧС.

Определить нормативы диагностирования для элементов пожарноспасательных автомобилей является сложной и трудоемкой задачей. Но за счет диагностирования элементов базового шасси, возможно существенно увеличить эффективность пожарно-спасательных автомобилей и безопасность их движения.

Традиционными объектами диагностирования являются составные агрегаты и узлы базовых шасси, такие как электрооборудование, двигатель, механизмы ходовой части и управления.

Требования к методам и средствам диагностирования данных узлов, которые использованы в пожарно-спасательных автомобилях не отличаются специфическими особенностями.

Поэтому возможно использовать разработанные серийные диагностические приборы и стенды, которые применяются при диагностировании транспортных автомобилей.

Наиболее эффектная система организации ТО и Р является плановопредупредительная система.

Сущность данной системы заключается в том, что периодичность технического обслуживания и ремонта и трудоемкость их работ заранее планируется. Но при этом техническое обслуживание проводят обязательном порядке, а ремонт производят по необходимости.

Чтобы организовать систему технического обслуживания и ремонта пожарно-спасательных автомобилей необходимо знать периодичность проведения работ и их трудоемкость. Чтобы определить трудоемкость работ 
ТО автомобиля применяют метод хронометрирования. Для обслуживания автомобиля определяется срок (в сутках), в течение которого оно должно быть произведено.

Величинами пробега пожарно-спасательного автомобиля или работы агрегата в часах регламентируется периодичность проведения ТО, которая определяется разными методами.

Но при этом существует ряд сложностей для определения периодичности ТО:

- зачастую в техническое обслуживание входит несколько видов работ: регулировочные, крепежные, смазочные, которые должны производиться с разной периодичностью;

- у каждого механизма и системы определена своя оптимальная периодичность обслуживания.

На рисунке 1 представлен график определения оптимальной периодичности ТО.

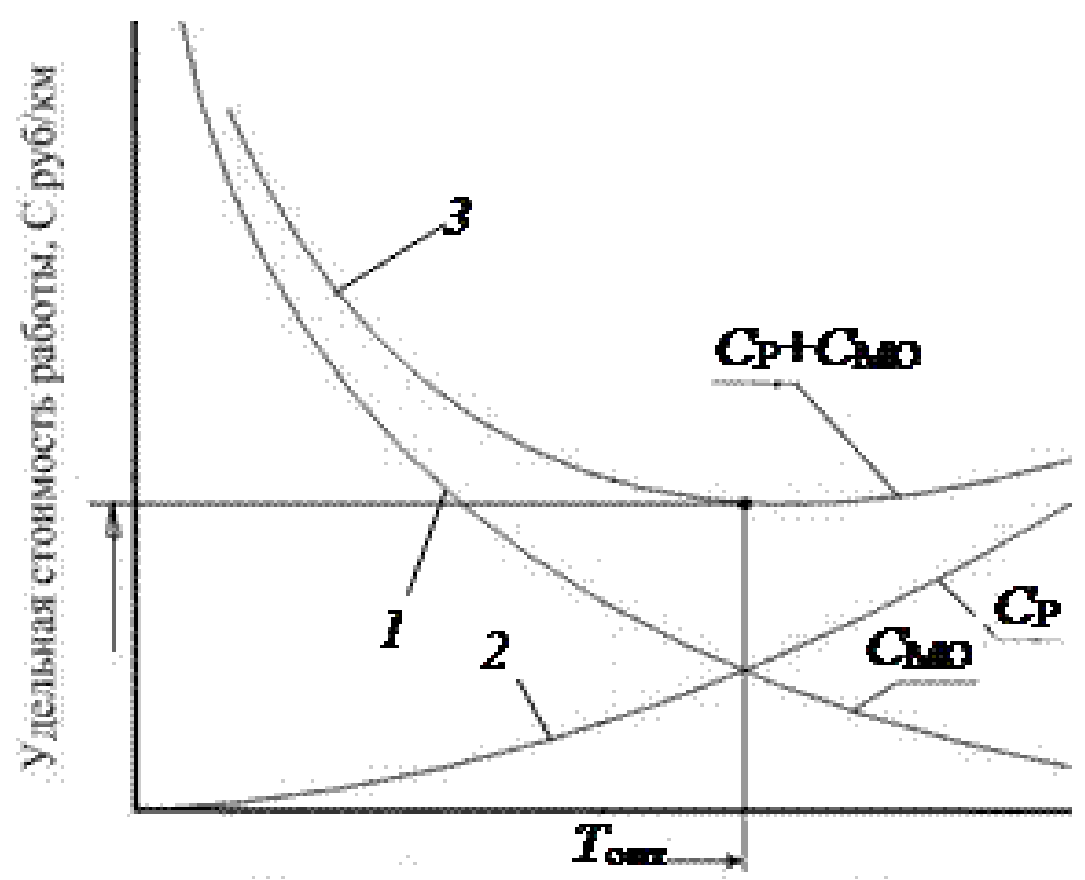

Рис. 1. Определение периодичности ТО

Как видно по кривой 1 (рисунок 1) чем больше пробег автомобиля, тем меньше удельная стоимость ТО. Но при этом, согласно кривой 2 , увеличиться удельная стоимость ремонта. Поэтому чтобы определить оптимальную периодичность ТО и Р можно воспользоваться кривой 3. 


\section{СОВРЕМЕННЫЕ ТЕХНОЛОГИИ: ПРОБЛЕМЫ ИННОВАЦИОННОГО РАЗВИТИЯ И ВНЕДРЕНИЯ РЕЗУЛЬТАТОВ}

Пожарно-спасательные автомобили, которые находятся на вооружении объектовых подразделений ГПС МЧС России, эксплуатируются при разных климатических условиях.

Климатические условия влияют на износ систем и агрегатов, из-за этого периодичность и трудоемкость работ для пожарно-спасательных автомобилей должны быть различны.

Так же на эффективность проведения ТО и Р влияет место эксплуатации пожарно-спасательных автомобилей. Так, например, согласно данных проведенных ВНИИПО, установили, что у пожарно-спасательных автомобилей, которые эксплуатируются в объектовых подразделениях меньше наработки, чем у автомобилей, которые эксплуатируются в пожарных частях населенных пунктов.

Так, например, у пожарных автоцистерн (далее АЦ) эксплуатируемых в объектовых частях общий годовой пробег составляет от 5,5 до 8,5 тыс.км. При этом для тех же АЦ эксплуатируемых в условиях города общий годовой пробег составляет от 10 до 12 тыс.км., что существенно выше.

Место эксплуатации пожарно-спасательных автомобилей влияет на режимы эксплуатации автомобиля, из-за чего различна степень износа систем и агрегатов автомобиля.

Так, например, АЦ на шасси ЗИЛ при эксплуатации в объектовых частях осуществляет выезд в город по 90-120 раз в год, а при эксплуатации в населенных пунктах данный показатель приближается к 150 выездам.

Отличается скорость движения пожарно-спасательных автомобилей. Так на объектах из-за плотной застройки технологическими сооружениями и установками, скорость движения пожарно-спасательных автомобилей зачастую ограничена 10-20 км/ч.

В условиях населенных пунктов скорость значительно выше, что приводит к большему износу узлов и агрегатов автомобиля, из-за большей вибрации, интенсивности трения узлов и т.д.

В населенных пунктах количество вызовов пожарно-спасательных автомобилей значительно меньше, чем в городе. Так, например, выезд АЦ в населенных пунктах составляет $30 \%$ на пожар, остальное количество выездов приходится на тренировки, учения, ТО и проведение дозоров. В городе данный показатель выездов на пожар существенно выше. 
Так же имеется отличие годовой наработки специальных агрегатов пожарно-спасательных автомобилей. Так в населенных пунктах данный показатель составляет 30 ч, а в городских условиях годовая наработка специальных агрегатов на 40\% больше.

Остальное время пожарно-спасательные автомобили находятся в режиме ожидания.

Исходя из проведенного анализа, можно сделать вывод о несоответствии фактических наработок пожарно-спасательных автомобилей между ТО-1 и ТО-2 экономически и технически обоснованным нормативами. Что свидетельствует о не несовершенстве системы планирования ТО.

Так, например, требование проводить один раз в месяц ТО-1 зачастую приводит к тому, что пожарно-спасательному автомобилю проводят техническое обслуживание без достаточной наработки, что влияет на увеличение себестоимости и трудоемкости проводимого технического обслуживания пожарно-спасательного автомобиля.

Для снижения себестоимости и трудоемкости ТО и $\mathrm{P}$ необходимо проводить оптимизацию периодичности и объемов работ по техническому обслуживанию и ремонту автомобиля, учитывая фактический ресурс агрегатов и систем, условия эксплуатации и объект подразделения автомобилей.

\section{Список литературы}

1. Говорущенко Н.Я. Диагностика технического состояния автомобилей. М.:- Транспорт, 1970. 254 с.

2. Михлин В.М. Методические указания по прогнозированию технического состояния машин. М.: Колос, 1972. - 216 с.

3. Минаев С.Н., Уткина Ж.Д. Показатели работы пожарных автомобилей и текущие расходы на эксплуатацию (справочные материалы к расчетам экономической эффективности). -Зкспресс инф. ВНИИПО, 1977, сер.П, вып.1 (71). 11 с.

4. Несвитский Я.И. Долговечность автомобиля М.: Автотранс-издат, 1963. - 45 c.

5. Техническая эксплуатация автомобилей / Под ред.Г.В.Крама-ренко М.: Транспорт, 1972.- 440 с. 